\title{
Terrestrial Gamma Radiation Exposure in Bangka-Belitung Islands, Indonesia
}

\author{
Syarbaini ${ }^{*}$ and A. Setiawan \\ Center for Technology of Radiation Safety and Metrology, National Nuclear Energy Agency, \\ Jl. Lebak Bulus Raya No.49, Jakarta 12440, Indonesia
}

\section{ARTICLE INFO}

\section{Article history:}

Received 27 August 2014

Received in revised form 05 March 2015

Accepted 30 March 2015

\section{Keywords:}

Natural radionuclides

Terrestrial gamma radiation

In situ measurements

Bangka Belitung

\begin{abstract}
A B S T R A C T
Bangka-Belitung is known as tin producer and it geologically contains higher concentrations of natural radionuclides than most other areas. The aim of this study was to evaluate the level of terrestrial gamma radiation in Bangka-Belitung Islands. The external gamma radiation dose rate from terrestrial gamma-rays have been measured at one meter above the ground by means of a portable gamma spectrometer at 66 survey points. The terrestrial gamma dose rates in Bangka island range from 43.67 to $511.54 \mathrm{nGy} \mathrm{h}^{-1}$ with a mean of $183.45 \mathrm{nGy} \mathrm{h}^{-1}$, while in Belitung island they range from 15.54 to $416.39 \mathrm{nGy} \mathrm{h}^{-1}$ with a mean of $132.60 \mathrm{nGy}$ $\mathrm{h}^{-1}$. From this work, a strong correlation was found between dose rates found from in-situ radiation measurements and dose rates calculated theoretically from radioactivity contents of the soil at the same locations. Generally, Bangka-Belitung islands have higher outdoor natural gamma dose rates than the world average value of $0.058 \mu \mathrm{Gy} \mathrm{h}{ }^{-1}$ for the regions with normal background radiation specified by United Nations Scientific Committee on the Effects of Atomic Radiation (UNSCEAR).
\end{abstract}

(C) 2015 Atom Indonesia. All rights reserved

\section{INTRODUCTION}

Terrestrial gamma radiation comes from two sources, namely terrestrial sources from radionuclides and extraterrestrial sources in the form of cosmic radiation. The terrestrial radionuclides include decay chain radionuclides, such as uranium$238\left({ }^{238} \mathrm{U}\right)$ and thorium- $232\left({ }^{232} \mathrm{Th}\right)$, and non-decay chain radionuclides, such as potassium- $40\left({ }^{40} \mathrm{~K}\right)$, which have been present in the earth (in rocks and soils) since its formation. The activity concentrations of these radionuclides in the soil and in the surrounding environment, as well as the associated external exposure due to the gamma radiation, depend primarily on the geological and geographical conditions of the region [1].

The Bangka-Belitung islands are known as a tin-producing area which forms a part of the Southeast Asian Tin Belt, the richest tin belt in the world which spans from South China - Thailand Myanmar - Malaysia to Indonesia. Tin is the

\footnotetext{
* Corresponding author.

E-mail address: sarbaini@batan.go.id
}

essential mineral resource of the Bangka-Belitung islands, with accessory minerals consisting of monazite, zircon, xenotime, ilmenite, magnetite and pyrite. Tin deposits are found as primary and secondary deposits [2].

Tin mining and processing of by-productheavy minerals from tin mining as contributed a number of natural radionuclides to the environment; this contribution occurs since those minerals, such as heavy mineral sand, monazite, ilmenite, zircon or xenotime, contain natural radioactive elements which co-exist with the tin ore or cassiterite in the ground [3-6].

The activity concentrations of natural radionuclides in soil of Bangka and Belitung islands have been previously reported [7]. Generally, the average and ranges of activity concentrations of radionuclides in soil collected from Bangka and Belitung islands are higher than the common areas world average, except for ${ }^{40} \mathrm{~K}$. The activity concentrations of ${ }^{226} \mathrm{Ra},{ }^{232} \mathrm{Th}$ and ${ }^{40} \mathrm{~K}$ are in the $4.8-544 \mathrm{~Bq} \mathrm{~kg}^{-1}, 7.3-2170 \mathrm{~Bq} \mathrm{~kg}^{-1}$, and $5.3-368$ $\mathrm{Bq} \mathrm{kg}{ }^{-1}$ ranges with mean values of $72.3,203$ and 
70.0 $\mathrm{Bq} \mathrm{kg}^{-1}$, respectively. World averages for ${ }^{226} \mathrm{Ra}$, ${ }^{232} \mathrm{Th}$ and ${ }^{40} \mathrm{~K}$ are $35 \mathrm{~Bq} \mathrm{~kg}^{-1}, 30 \mathrm{~Bq} \mathrm{~kg}{ }^{-1}$ and $400 \mathrm{~Bq}$ $\mathrm{kg}^{-1}$ respectively. The previous study was also carried out to evaluate the natural radioactivity concentration in some food crops grown in Bangka and Belitung Islands. There was an indication that the mining activities in Bangka-Belitung islands impacted the radiation burden of the environment [8].

The activity of tin dressing and refining during the past years which spread over the BangkaBelitung areas may cause the enhancement of the environmental dose rate due to natural radionuclides. In this study, the distribution of outdoor gamma dose rates from terrestrial gamma radiation in Bangka-Belitung islands and their effective dose rates were investigated.

\section{EXPERIMENTAL METHODS}

\section{Site descriptions}

Geographically, Bangka - Belitung Islands are located at $104^{\circ} 50^{\prime}-109^{\circ} 30^{\prime} \mathrm{E}$ and $0^{\circ} 50^{\prime}-4^{\circ} 10^{\prime}$ $\mathrm{S}$. The total area of Bangka-Belitung Islands is about $81,725.14 \mathrm{~km}^{2}$, consisting of a land area of about $16,424.14 \mathrm{~km}^{2}$ or 20.1 percent of the total area and a sea area of about $65,301 \mathrm{~km}^{2}$ or 79.9 percent of the total area. The Bangka Strait separates Sumatera Island from Bangka Island whereas the Gaspar Strait separates Bangka Island from Belitung Island. North of the islands liesthe South China Sea, to the south lies the Jawa Sea, and Kalimantan Island lies in the east, separated from Belitung Island by the Karimata Strait.

In general, the topography of BangkaBelitung is relatively flat, mostly ranging from lowlands to hilly lands, with only a small part of the islands being mountainous. The altitude of the lowland is around $50 \mathrm{~m}$ above the sea level. The highest point in the Bangka Island is in the pinnacle of Maras Mountain at an altitude of 699 meter, while in Belitung Island it is in the Tajam Mountain with an altitude of $500 \mathrm{~m}$ above the sea level [9].

\section{Measurement points}

The sampling points were selected by dividing each of the total area of the Bangka and Belitung islands using a square grid as reported previously [7]. Geographical coordinates of sampling points were determined using a $60 \mathrm{CHx}$ global positioning system (GPS) map manufactured by Garmin.

\section{Gamma dose rate}

The gamma dose rate was measured at one meter above the ground by means of a portable gamma spectrometer (Model GR-130 Mini Spec, produced by Exploranium Company, Canada). The instrument was calibrated by a secondary standard dosimetry laboratory under the National Nuclear Energy Agency of Indonesia. For statistical purposes, 10 readings were taken at each point of reading and the average was recorded. Further, some environmental parameters such as temperature, pressure, relative humidity and weather conditions at the time of measurement were recorded.
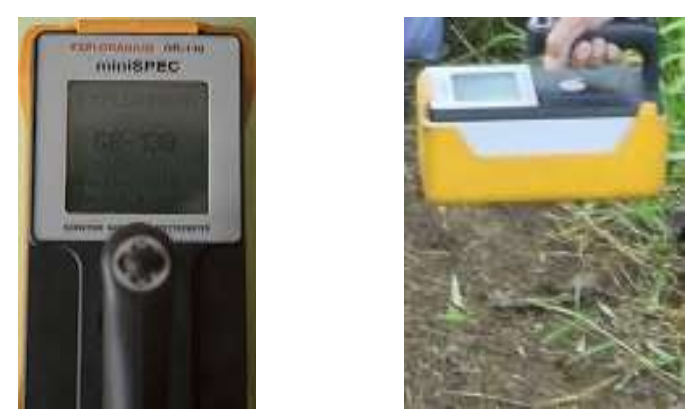

Fig. 1. MiniSpec Exploranium GR 130.

\section{RESULTS AND DISCUSSION}

The terrestrial gamma dose rate measurements at one meter above surface soil in Bangka and Belitung islands were found to be varying in different sites. The terrestrial gamma dose rate of Bangka Island ranged from 43.67 to $511.54 \mathrm{nGy} \mathrm{h}^{-1}$ with a mean of $183.45 \mathrm{nGy} \mathrm{h}^{-1}$, while for Belitung island it ranged from15.54 to $416.39 \mathrm{nGy} \mathrm{h}^{-1}$ with a means of $132.60 \mathrm{nGy} \mathrm{h}^{-1}$.

The distribution of terrestrial gamma dose rate data is presented as a histogram in Figs. 2 and 3 . The histogram shows the variation of terrestrial gamma absorbed dose rates measured in various areas in Bangka-Belitung. It can be seen that generally the averages and ranges of gamma dose rate in Bangka Island are higher than those in Belitung island. High values of terrestrial gamma dose rate in Bangka may correlate with the differences in the patterns of mineralization between the two islands. In Bangka Island, mineralizations formed around granite bodies, and tin deposits are found mainly in contact zones. In Belitung Island, mineralizations formed far from the granite bodies. The altitude of the island above the sea level during the Tertiary and Quaternary period also contributed to the weathering intensity, which influenced the characteristics and existence of the primary mineral deposits $[2,7]$. 
Additionally, the increasing tin mining activities by individuals and illegal mines in Bangka-Belitung islands may also be responsible for the enhanced radioactivity in the area. Generally, tin mining leaves some natural radionuclides which easily transfers from the mining location to its surrounding environment which goes up to the land surface [10-12].

All surveyed areas (Bangka-Belitung) showed considerably higher ambient gamma dose rates, compared with the global outdoor natural gamma dose rate average of $0.058 \mu \mathrm{Gy} \mathrm{h}^{-1}$ [13]. It may be caused by the possible rise in concentration due to the accumulation of mineral sands from various mining activities in Bangka-Belitung islands. The soil in Bangka-Belitung is severely degraded due to uncontrolled mining. Illegal mining is the main cause of land degradation. The rapidly increasing number of illegal mines is a large contributor to the destruction of the Bangka-Belitung soil [14].

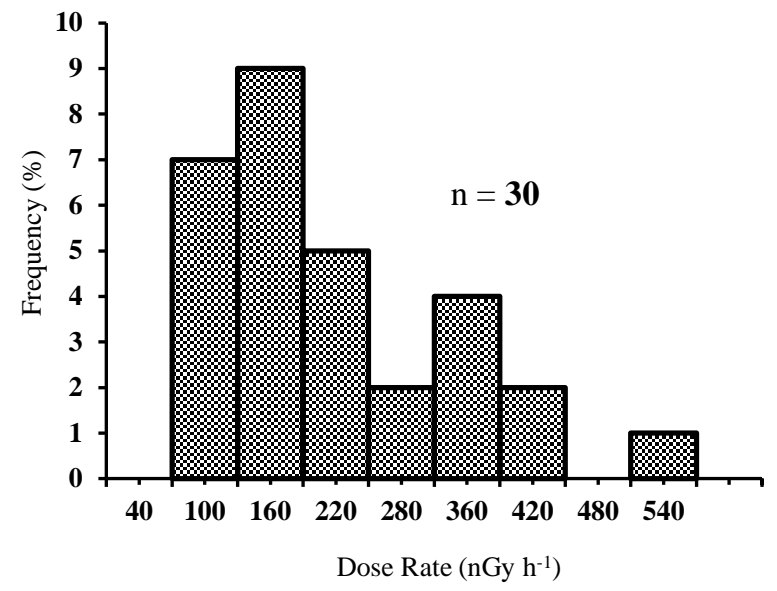

Fig. 2. Frequency histogram of dose rate in Bangka

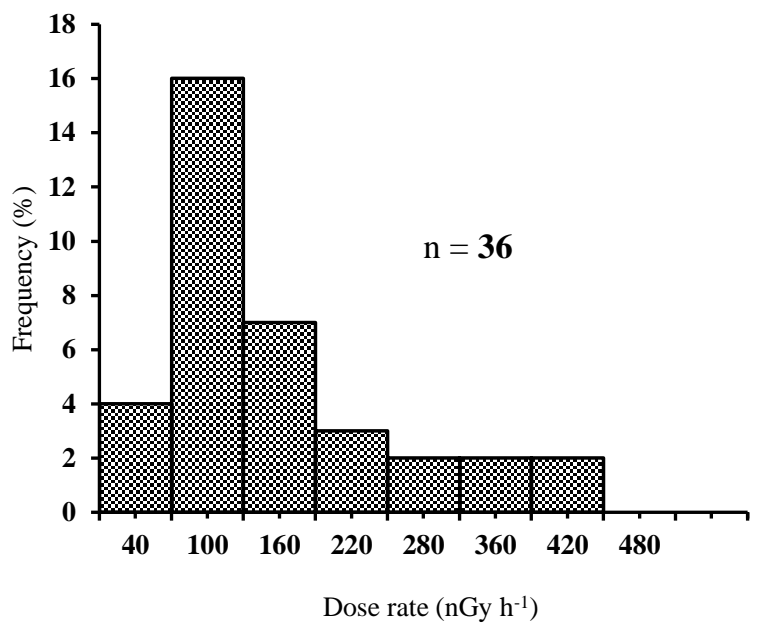

Fig. 3. Frequency histogram of dose rate in Belitung
The results of direct measurements of the terrestrial gamma dose rate were compared with the results of calculations based on the concentration of radionuclides in soil samples as shown in Figs. 4 and 5. The values of outdoor air-absorbed dose rates which was calculated based on the concentrations of ${ }^{226} \mathrm{Ra},{ }^{232} \mathrm{Th}$, and ${ }^{40} \mathrm{~K}$ in soil collected from the same site with present work have been previously reported [7].

The outdoor air-absorbed dose rates due to terrestrial gamma rays at $1 \mathrm{~m}$ above the ground level have been calculated from ${ }^{226} \mathrm{Ra},{ }^{232} \mathrm{Th}$ and ${ }^{40} \mathrm{~K}$ concentrations in the soil by using the following formula [15-18]:

$$
D\left(n G y h^{-1}\right)=0.462 A_{R a}+0.604 A_{T h}+0.0417 A_{K}
$$

Where $\mathrm{D}$ is the absorbed dose rate in $\mathrm{nGy} \mathrm{h}^{-1}$, and $A_{R a}, A_{T h}$ and $A_{K}$ are the specific activities of ${ }^{226} \mathrm{Ra},{ }^{232} \mathrm{Th}$, and ${ }^{40} \mathrm{~K}$, respectively, in $\mathrm{Bq} \mathrm{kg}^{-1}$. The conversion factors $0.462,0.604$, and 0.0417 are the corresponding dose conversion coefficients which convert the specific activities to absorbed dose rates; they are expressed in nGy $\mathrm{kg} \mathrm{h}^{-1} \mathrm{~Bq}^{-1}$. These coefficients were originally derived from Monte Carlo simulations using mathematical phantoms $[1,19]$.

Figures 4 and 5 show the correlations found between dose rates obtained from in-situ radiation measurements and dose rates theoretically calculated from radioactive contents of soils at the same locations. As can be seen in Figs. 4 and 5, the relationship between dose rates calculated from concentrations of ${ }^{226} \mathrm{Ra},{ }^{232} \mathrm{Th}$ and ${ }^{40} \mathrm{~K}$ in soil samples of Bangka-Belitung and dose rates obtained using a MiniSpec Exploranium GR 130 gamma ray spectrometer at the same sites showed high correlation coefficients $(\mathrm{r}=0.8526$ and 0.8883 ). A reasonable relationship can be seen. Plots of the two variables $(x=$ theoretical, $\mathrm{y}=$ experimental) used in the study showed that they were linearly related. The intercept might be explained as the contribution from cosmic rays to the measured gamma dose rate [20]. Besides that, natural radionuclides may not be distributed uniformly in the soil; radon and its decay products in the atmosphere may affect dose rates; soil moisture of the surface layer may affect dose rates; and the soil samples were analyzed after removal of pebbles and stones [21]. 


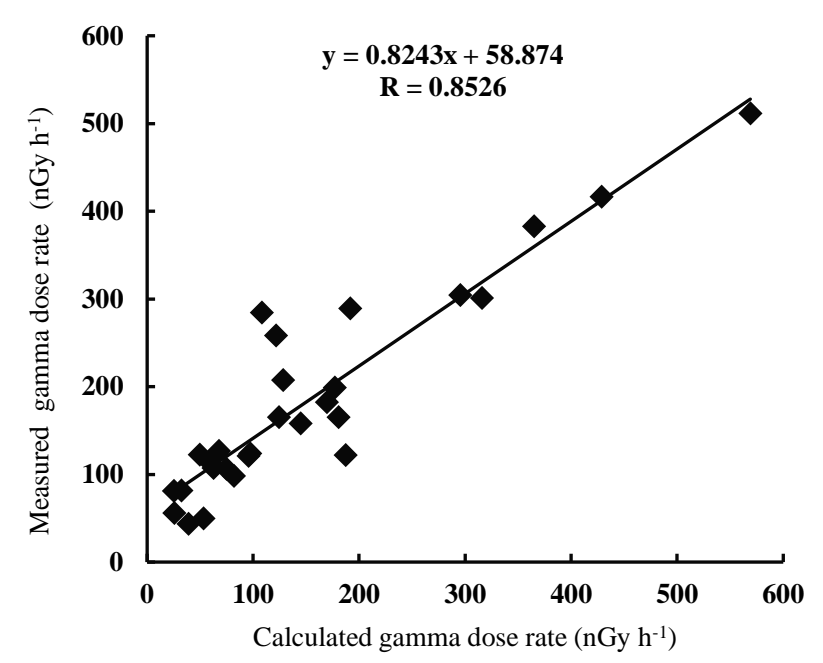

Fig. 4. Relationship between directly measured dose rates and dose rates calculated from concentration of ${ }^{226} \mathrm{Ra},{ }^{232} \mathrm{Th}$ and ${ }^{40} \mathrm{~K}$ in soil samples from Bangka.

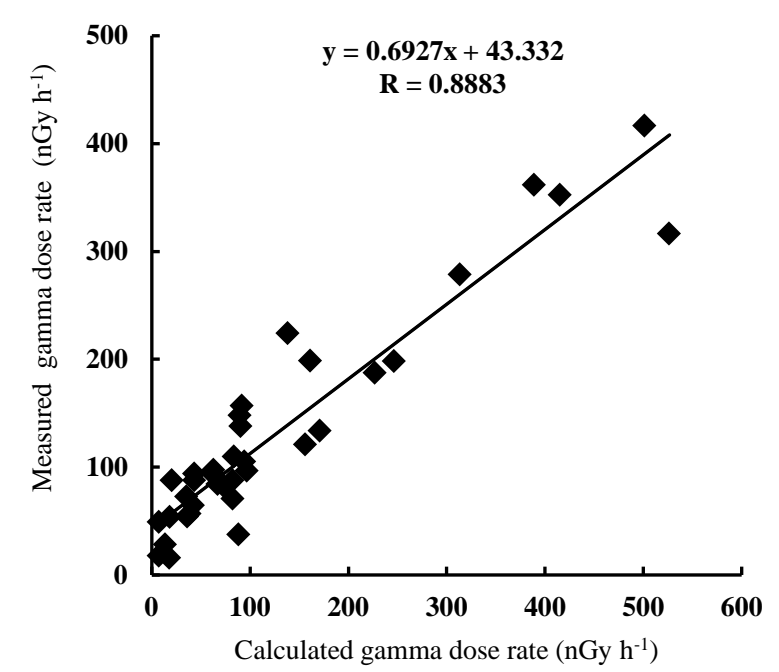

Fig. 5. Relationship between directly measured dose rates and dose rates calculated from concentration of ${ }^{226} \mathrm{Ra},{ }^{232} \mathrm{Th}$ and ${ }^{40} \mathrm{~K}$ in soil samples from Belitung

Further, the in-situ measured data of terrestrial gamma dose rates were mapped using Surfer GIS software to simulate the whole Bangka-Belitung region. The resulting map of terrestrial gamma dose rate is shown in Fig. 6; it shows the distribution of terrestrial gamma absorbed dose rates measured in various places in the Bangka-Belitung islands. It can be seen from Fig. 6 that the higher gamma dose rates are found in the region of Bangka island and in the western part of Belitung island. It may be influenced by many factor such as the differences in soil characteristics, geological conditions of the island, and mining activities.

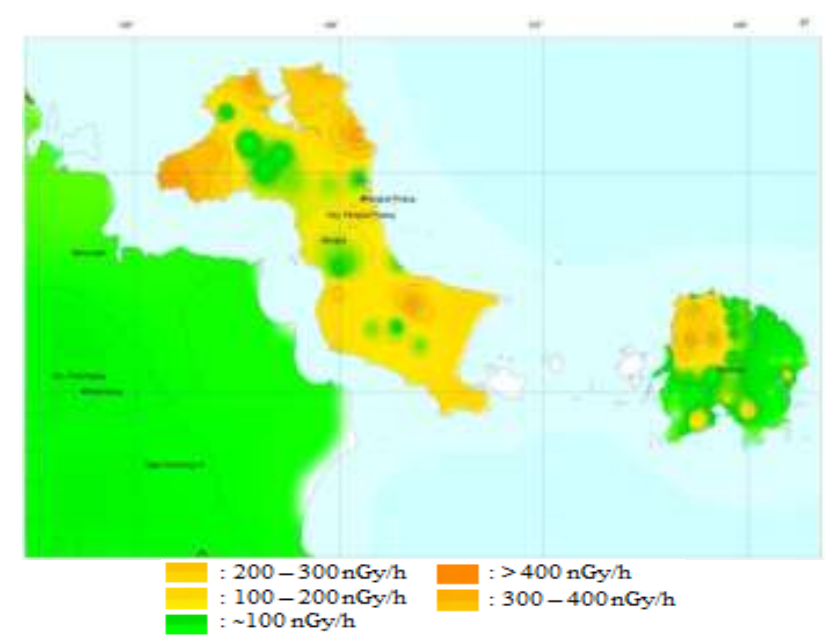

Fig. 6. The map of terrestrial gamma dose rate of BangkaBelitung Islands.

\section{CONCLUSION}

The terrestrial gamma dose rates varied considerably within the study area, even among adjacent regions. This variation is associated with the distribution of radionuclide activity concentrations of the soil. It has been observed that there was a good correlation between direct measured dose rates and calculated terrestrial dose rates in all sites. Generally, the average and ranges of the terrestrial gamma dose rate the whole Bangka and Belitung islands are higher than the world average.

\section{ACKNOWLEDGMENT}

The author would like to thank Mr. Kusdiana, Staff of the Radioecology Division, Center for Technology of Radiation Safety and Metrology, National Nuclear Energy Agency, Indonesia for his support in preparing the contour map in this study. The author also gratefully acknowledges all staff of the Environmental Safety group, Radioecology Division, for their technical assistance.

\section{REFERENCES}

1. Anonymous, Exposures from Natural Radiation Sources, in: Sources and Effects of Ionizing Radiation, United Nations Scientific Committee on the Effects of Atomic Radiation (UNSCEAR) Report, Vol. I, Annex B, United Nations publication, New York (2000) 89. 
2. M. O. Schwartz, S. S. Rajah, A. K. Askury, et al., Earth-Science Reviews 38 (1995) 95.

3. A.M. Arogunjo, V. Hollriegl, A. Giussani, et al., J. Environ. Radioact. 100 (2009) 232.

4. I.G.E. Ibeanu, J. Environ. Radioact. 64 (2003) 59.

5. N.N. Jibiri, I.P. Farai and S.K. Alausa, J. Environ. Radioact. 94 (2007) 331.

6. I. Bahari, N. Mohsen and P. Abdullah, J. Environ. Radioact. 95 (2007) 61.

7. Syarbaini, Kusdiana and D. Iskandar, International Journal of Sustainable Energy and Environment 3 (2015) 1.

8. Syarbaini, A. Warsona and D. Iskandar, Atom Indonesia 40 (2014) 27.

9. Anonymous, Climate and Topography http://www.babelprov.go.id/content/iklimdan-topografi, Retrived in April 2015.

10. A.M. Arogunjo, V. Hollriegl, A. Giussani, et al., J. Environ. Radioact. 100 (2009) 232.

11. A.J. Innocent, M.Y. Onimisi and S.A. Jonah, British Journal of Applied Science and Technology 3 (2013) 684.

12. I.R. Ajayi, Iran J. Radiat. Res. 5 (2008) 203.

13. Anonymous, Exposures from Natural Sources of Radiation, in: Sources, Effects and Risks of Ionizing Radiation, United Nations Scientific Committee on the Effects of Atomic Radiation (UNSCEAR) Report, Annex A, United Nations publication, New York (1988) 57
14. M. Sidabukke, Illegal Tin Minning at Protection Forest Area (Case Study at Protection Forest Area of Sepang Mountain, Badau, Bangka Belitung), Ph.D. Thesis, University of Indonesia (2011).

15. Anonymous, Exposures from Natural Sources of Radiation, in: Sources and Effects of Ionizing Radiation, United Nations Scientific Committee on the Effects of Atomic Radiation (UNSCEAR) Report, Annex A, United Nations publication, New York (1993) 65.

16. D.C. Kocher and A.L. Sjoreen, Health Phys. 48 (1985) 193.

17. S. Singh, A. Rani and R.K. Mahajan, Radiation Measurements 39 (2005) 431.

18. H.A. Al-Sulaiti, Determination of Natural Radioactivity Levels in the State of Qatar Using High-Resolution Gamma-ray Spectrometry, Ph.D. Thesis, Surrey University (2011).

19. Anonymous, Exposure to Natural Radiation Sources, in: Ionizing Radiation Sources and Biological Effects, United Nations Scientific Committee on the Effects of Atomic Radiation (USNCEAR) Report, Annex B, United Nations publication, New York (1982) 87.

20. M.A. Saleh, A.T. Ramli, Y. Alajerami, et al., J. Environ. Radioact. 124 (2013) 130.

21. K. Chikasawa, T. Ishii and H. Sugiyama, J. Health Science 47 (2001) 362. 